\section{Clinical Treatment of the Digestive Form of Chagas Disease}

\section{Ulysses G Meneghelli}

\author{
Departamento de Clínica Médica, Faculdade de \\ Medicina de Ribeirão Preto, USP, Av. Bandeirantes \\ 3900, 14049-900 Ribeirão Preto, SP, Brasil
}

Key words: chagas disease - digestive form

The digestive form of Chagas disease, first individualized by JM Rezende (1959 Rev Goiana Med 5: 193), represents, together with the cardiac form, the most important manifestation of the chronic phase of Trypanosoma cruzi infection.

The anatomopathologic basis of the digestive form of Chagas disease is denervation of the complex network of intramural neurons (M Amorin \& A Correia Neto 1932 An Fac Med São Paulo 8: 101, E Etzel 1934 An Fac Med São Paulo 10: 631, F Köberle 1968 Adv Parasitol 6: 63), today known as enteric nervous system. This fact was demonstrated not only by the detailed histological studies cited above, but also by in vivo denervation tests involving the administration of drugs with a cholinergic action (RA Godoy \& CB Vieira 1961 Acta Physiol Lat Amer 11: 107, CB Vieira \& R A Godoy 1963 Rev Goiana Med 8: 21, UG Meneghelli 1968 Rev Goiana Med 14: 61). The nervous system plays a fundamental role in the regulation of the motor functions of the digestive tube. Consequently, its destruction causes disorders in the motility of the affected organ. The esophagus and sigmoid colon are preferentially affected by denervation.

From a physiological viewpoint, motor dysfunction is characterized, since the pre-ectasic phases, by the presence of lower sphincter achalasia and by the loss of peristaltic organization of the movements of the esophageal body, and by reduction of the response to physiological stimuli and basal hypomotility in the colon. The esophageal abnormalities may not arise simultaneously during the course of the disease (UG Meneghelli 1996 XXXIV Cong Brasil Gastroenterol, Goiânia).

Fax: +55-16-633.6695. E-mail: ugmenegh@fmrp.usp.br Received 9 June 1999

Accepted 9 August 1999
The symptomatic clinical manifestations of the digestive form of Chagas disease are expressed as dysphagia in the presence of esophagopathy and as intestinal constipation in the presence of colonic disease. The most notable structural consequences of the denervation caused by these pathologies are megaesophagus and megacolon, respectively.

The treatment of esophagopathy and of colonic disease can be clinical, surgical and, in the case of esophagopathy, may also involve procedures for cardia dilatation. Whatever the treatment used, it will necessarily be symptomatic since the basic lesion of the disease is neuronal destruction, which is irreversible.

\section{TREATMENT OF ESOPHAGOPATHY}

The indications for clinical treatment of chagasic esophagopathy are as follows: (1) when dysphagia is well tolerated, of low intensity or intermittent. It should be remembered that the course of non-dilated esophagopathy is slow for the various groups of megaesophagus, or the condition may not even occur. This permits patient follow-up for a long time, so that more aggressive therapeutic measures may be taken in an unhurried manner, after considerable reflection and especially after the patient expresses the wish to be submitted to them. In addition to being informed about the benefits of invasive treatment, the patient should also be aware of the limitations and the undesirable effects possibly involved in these procedures. These therapeutic interventions should be executed by competent personnel in order to achieve good results; (2) as long as adequate functioning of the lower esophageal sphincter persists, as detected by manometry; (3) while the patient is waiting for surgical treatment; (4) when the dilatation of the organ is within group II of the megaesophagus classification; (5) when the patient would be at risk if submitted to other treatment alternatives.

Clinical treatment first involves clarification of the nature and course of the disease for the patient, information about the therapeutic possibilities, and tranquilization. Many patients fear the possibility of having or of acquiring chagasic cardiopathy and should be informed and reassured about this aspect. When emotional tension or anxiety is observed, anxiolytics can be prescribed. The patient should be instructed to eat slowly, to ingest preferentially pasty or liquid foods, or, when eating solid foods, to chew them well and to accompany or follow them with water ingestion. A good natural or artificial set of teeth is imperative. Irritating foods or excessively hot or cold foods should be avoided.

Patients who present marked esophageal retention should take the last meal of the day at least 2 
$\mathrm{hr}$ before going to bed in order to avoid regurgitation and aspiration of esophageal content into the lower airways.

Drugs that act as relaxants of the lower esophageal sphincter have been studied as possibilities of treatment of chagasic esophagopathy. Botulin toxin acts by inhibiting acetylcholine release. When applied locally at the level of the lower sphincter by the endoscopic route, botulin toxin has shown favorable results in idiopathic achalasia (C Cuillère et al. 1997 Gut 41: 87). It should be remembered that in this disease denervation spares the cholinergic neurons. Since this does not occur in chagasic esophagopathy, the prediction is that the results would not be so favorable. This is still an experimental procedure.

Isosorbitol dinitrate, a nitrate that relaxes smooth muscle, administered sublingually at the dose of 5 or $2.5 \mathrm{mg}$ causes a marked reduction of lower esophageal sphincter pressure in chagasic patients for approximately $60 \mathrm{~min}$ (RO Dantas et al. 1987 Arq Gastroenterol 24: 84). At these doses, isosorbitol dinitrate accelerates megaesophagus emptying (J Rezende Filho et al. 1990 Arq Gastroenterol 27: 115) and is effective in the control of dysphagia in these patients (LP Ferreira Filho et al. 1991 Brazil J Med Biol Res 24: 1093). Its side effects are headache and gastroesophageal reflux since the sphincter remains relaxed for a long time. In patients with chagasic esophagopathy, es- tablished reflux maintains the intraesophageal $\mathrm{pH}$ reduced for a longer time than in the esophagus of normal persons because the aperistalsis of the esophageal body impairs acid clearance (NM Matsuda et al. 1995 Dig Dis Sci 40: 177). Current experience with isosorbitol dinitrate is limited to its application for short periods of time (weeks), and its long-term effects are unknown. There is the possibility that the responses to the drug will be progressively lower with time (tachyphylaxis), thus limiting its use.

\section{TREATMENT OF COLONIC DISEASE}

Clinical treatment is indicated for: (1) patients with mild or moderate intestinal constipation; (2) uncomplicated megacolon; (3) patients at high risk for surgical procedures. Clinical treatment is based on the use of laxatives. The laxatives used can be those that stimulate colon motility such as phenolphthalein, sene, sodium picosulfate and cascara sagrada, or those with a lubricating or emollient action such as mineral oils. Intestinal lavage with water and glycerin (10:1) or mini-enemas available at drugstores can also be used frequently or occasionally.

Although this has not been proven, it has been proposed that the regular use of laxatives and/or lavage may retard the formation of megacolon or, when the latter is already present, may reduce the incidence of fecalomas and of other complications. 